\title{
Modelling of Stirrup Confinement Effects in RC Layered Beam Finite Elements Using a 3D Yield Criterion and Transversal Equilibrium Constraints
}

\author{
Péter Zoltán Berke ${ }^{*}[0]$ and Thierry Jacques Massart
}

\begin{abstract}
Apart from its recognized strengthening effect for shear loading, the presence of stirrups in reinforced concrete results in an increase of the ductility of structural members and in the capacity of reaching higher longitudinal compressive stress levels provided by transversal confinement. These effects are usually represented phenomenologically in fibre beam models by artificially increasing the compressive strength and the ultimate compressive strain of concrete. Two numerical formulations for layered beam descriptions accounting explicitly for transversal confinement are implemented and assessed in this contribution. The influence of stirrups is incorporated by means of a multi-dimensional yield surface for concrete, combined with equilibrium constraints for the transversal direction involving concrete and steel stirrups, and with a concrete ultimate strain dependent on the hydrostatic stress. This contribution focuses on the numerical formulations of both frameworks, and on their assessment against experimental results available in the literature.
\end{abstract}

Keywords: reinforced concrete confinement, stirrups, layered beam model, transversal equilibrium constraint, multiaxial yield criterion

\section{Introduction}

The robustness of reinforced concrete structures is highly dependent on their capacity to deform in a ductile manner. One of the most important design considerations for ensuring ductility is the provision of transverse reinforcements (stirrups) in order to postpone shear failure and to prevent buckling in columns. Even though stirrups have been used for decades, several questions, such as obtaining the most efficient geometrical stirrup distribution, is still subject of ongoing research (Ding et al. 2011; Corte and Boel 2013; Breveglieri et al. 2015). Stirrups exert lateral compressive stresses on concrete as it expands in the transversal directions due to loading, which improves the structural members strength and ductility. In several

\footnotetext{
*Correspondence: pberke@ulb.ac.be

Building, Architecture and Town Planning (BATir) department, Université libre de Bruxelles (ULB), CP 194/2, Av. F.D. Roosevelt 50, 1050 Bruxelles, Belgium

Journal information: ISSN 1976-0485 / eISSN 2234-1315
}

scenarios the ductility of the reinforced concrete members is of utmost importance, such as in progressive collapse (Menchel et al. 2009; Hou and Song 2016; Petrone et al. 2016; Rashidian et al. 2016) and resistance against blast loading (Lim et al. 2016; Codina et al. 2016).

The material response of confined concrete is a research topic with a long history, dating back to the 1920s. Research on concrete cylinders confined by hydrostatic pressure or by spiral stirrups was conducted in Richart et al. $(1928,1929)$, corresponding to one of the pioneering works in the field. Different researchers, such as in Kent and Park (1971), Sargin (1971), Sheikh and Uzumeri (1980), Ahmad and Shah (1982), Park et al. (1982), Scott et al. (1982), Mander et al. (1988a, b), Xiao (1989), Saatcioglu and Razvi (1992), Cusson and Paultre (1995), Hong and Han (2005), carried out experimental and theoretical work on the behaviour of confined concrete and developed several analytical models. Some constitutive models 
derived from these experiments are employed in building codes for confined concrete behaviour. Yet such models do not allow considering all situations for numerical nonlinear analyses that involve multi-axial loading, since they do not cover all possible stress conditions.

The behaviour of concrete under multi-axial stress conditions was intensively studied to develop a general criterion for irreversible material response (Buyukozturk and Tseng 1984; Imran and Pantazopoulou 1996; Sfer et al. 2002; Tan 2005; Lu 2005; Gabet et al. 2008; Malécot et al. 2010; Hammoud et al. 2014; Zhou et al. 2014) (plasticity and/or failure). Numerous types of concrete failure criteria have been developed, aimed at defining an adequate shape of the limit surface (Chen 1982; Comi 2001; Cho and Park 2003; Dede and Ayvaz 2010; Comi et al. 2012; Bao et al. 2013). For quasi-brittle materials like concrete, the failure criterion is affected by the hydrostatic stress, including the effect of the lateral stresses generated by stirrups in reinforced concrete members. The fact that the strength of concrete with active confinement by fluid pressure was observed to be similar to that of concrete with stirrups (Richart et al. 1929) also confirms that the consideration of the multi-axial behaviour of concrete should be taken into account in the representation of the effects of stirrups. Several contributions addressed the multi-axial behaviour of concrete in the modelling of the structural response of reinforced concrete members with stirrups (Cho and Park 2003; Saritas and Filippou 2009; Garzón-Roca et al. 2012). Other existing formulations proposed in Petrangeli et al. (1999), Mullapudi and Ayoub (2010), Stramandinoli and Rovere (2012), Mullapudi and Ayoub (2013) used layered (2D)/fibre (3D) beam models. These works focused on the incorporation of shear deformation, and used a force-based approach with the softened membrane model (Mullapudi and Ayoub 2010, 2013) or modified compression field theory (Stramandinoli and Rovere 2012). In Petrangeli et al. (1999), Mullapudi and Ayoub (2010), Stramandinoli and Rovere (2012) a biaxial stress state was assumed for concrete in beam elements for planar frames with a single transversal equilibrium condition, while (Mullapudi and Ayoub 2013) takes the triaxial stress state into account in a 3D formulation.

The primary goals of the present contribution are the implementation and assessment of two novel stirrup confinement formulations with different assumptions of the transversal equilibrium. This is achieved in a physicallybased layered beam finite element model involving the axial and the lateral reinforcements, and a triaxial constitutive law for concrete. The present work is based on a novel combination of numerical ingredients not yet applied to the study of stirrups effects. A displacement-based 2D layered beam formulation (Santafé Iribarren et al. 2011;
Zendaoui et al. 2016) is used with Bernoulli kinematics in a corotational framework. It involves a triaxial stress state for concrete, solving two simultaneous transversal equilibrium constraints in the beam cross section. Additionally, a dependency of concrete ultimate strain on the hydrostatic stress is postulated, which governs the failure by crushing of the concrete layers in the model. A special emphasis is given to the validation of the implemented numerical model through qualitative and quantitative comparison with experimental data reported in the literature.

\section{Computational Framework}

\subsection{Corotational Layered Beam Finite Element}

A Bernoulli layered beam finite element for planar frames is used here, without loss of generality for the applicability of the concepts to other beam kinematics. For clarity, the main governing equations are briefly recalled, with more details available in Crisfield (1995), Battini (2002), Oliveira et al. (2014), Oliveira (2015).

The beams are assumed contained in the $(x, y)$ plane, $z$ is the out-of-plane direction. A corotational framework is used to incorporate large rotations and catenary actions. Strains are therefore computed in a rotating reference frame attached to the finite element to uncouple the rigid body rotation from physical strains. Assuming that strains remain small in the local frame, the axial, $u_{l a}$, and transversal displacements, $v_{l t}$, in the rotated element axes are interpolated using linear and cubic shape functions, respectively. The average axial strain, $\bar{\epsilon}(x)=\frac{\partial u_{l a}(x)}{\partial x}$ and the beam curvature $\chi(x)=\frac{\partial^{2} v_{l t}(x)}{\partial x^{2}}$, i.e., the generalized strains $\mathbf{E}=\{\bar{\epsilon}, \chi\}^{T}$ are evaluated with a three point Gauss integration scheme.

The beam cross section is discretized in layers of finite height. The axial strain in a given layer $i$ is obtained considering the Bernoulli beam kinematics according to:

$$
\epsilon_{x}^{i}=\bar{\epsilon}-\bar{y}^{i} \chi
$$

where $\bar{y}^{i}$ is the position of the layer center of mass with respect to the neutral axis of the total beam section (Fig. 1). For simplicity, the bond between concrete and steel reinforcement is assumed perfect, resulting in axial strain compatibility in each layer. The assumptions made on the transversal strains are presented in Sects. 2.4 and 2.5 .

The average axial stress in a layer $i, \sigma_{x}^{i}$, is obtained using a weighted average of the axial stress of concrete and of steel 


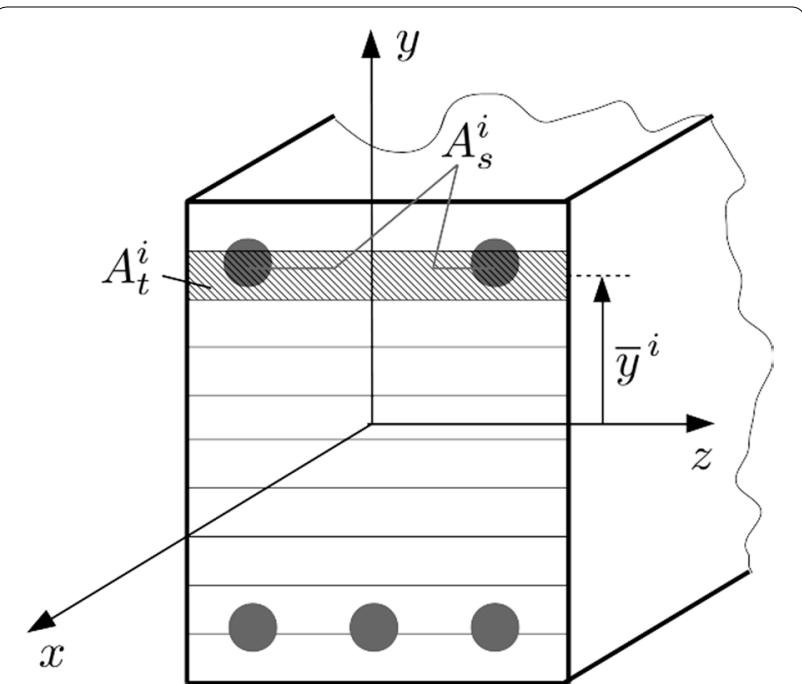

Fig. 1 Axial beam cross section discretized into layers along the beam height (stirrups are not shown) with $A_{t}^{i}$ and $A_{t}^{i}$ the total and the steel area in layer $i$, respectively.

$$
\sigma_{x}^{i}=\left(1-\Omega_{s}^{i}\right) \sigma_{x}^{c i}+\Omega_{s}^{i} \sigma_{x}^{s i}
$$

with $\Omega_{s}^{i}=\frac{A_{s}^{i}}{A_{t}^{i}}$, the surface fraction of the longitudinal steel reinforcement in layer $i$, and $\sigma_{x}^{c i}$ and $\sigma_{x}^{s i}$ the axial stress developed in concrete and steel in that layer, respectively. When the presence of stirrups is not taken into account explicitly the computation of stresses in steel and concrete can be performed using two separate uniaxial problems. When stirrups are considered this no longer is the case, as it will be explained in Sects. 2.4 to 2.5 .

Based on longitudinal layer stresses, the generalized stresses at an integration point, $\Sigma=\{N, M\}^{T}$, are obtained from a finite sum over all of the layers in the beam cross section defined by:

$$
\left\{\begin{array}{l}
N=\sum_{\substack{i=1 \\
n_{\text {lay }}}}^{n_{\text {lay }}} \sigma_{x}^{i} A_{t}^{i} \\
M=\sum_{i=1}^{i} \sigma_{x}^{i} A_{t}^{i}
\end{array}\right.
$$

where $N$ and $M$ are the axial force and bending moment conjugated to $\bar{\epsilon}$ and $\chi$ respectively, and $n_{\text {lay }}$ is the number of layers in the beam cross section. Generalized stresses are then used to compute the internal force vector of the element.
The structural problem is solved using a Newton-Raphson incremental-iterative scheme. This requires the derivation of the structural tangent stiffness matrix of the elements, that is composed of contributions from the change in geometry and from the sectional tangent stiffness relating the variation of the generalized stresses to the variation of the generalized strains, $[H]_{\sec }=\frac{\partial \Sigma}{\partial \mathbf{E}}$. This sectional tangent stiffness can be obtained from the scalar valued material tangent stiffness, $H^{i}$, of each layer $i$, computed from the axial material tangent stiffness of each material using:

$$
H^{i}=\left(1-\Omega_{s}\right) h_{x}^{c i}+\Omega_{s}^{i} h_{x}^{s i}
$$

with $h_{x}^{c i}$ and $h_{x}^{s i}$ the (scalar) material tangent stiffness of concrete and steel in the axial direction.

\subsection{Constitutive Behaviour for Steel and Concrete}

A unidimensional description, i.e. these elements work in pure tension or in pure compression, is used to model the response of the steel reinforcements and stirrups with an elasto-plastic behaviour. The buckling of steel bars under compression is disregarded. The stress in the steel bars placed in the axial, $\sigma_{x}^{s}\left(\epsilon_{x}\right)$, and in the two transversal directions, $\sigma_{y}^{s}\left(\epsilon_{y}\right)$ and $\sigma_{z}^{s}\left(\epsilon_{z}\right)$, is obtained using three separate unidimensional return-mapping operations when in the plastic domain. The material response is assumed symmetric in tension and in compression with isotropic hardening defined by:

$$
\sigma_{Y}^{s}=\sigma_{0}^{s}\left(1+K \kappa^{s}\right)^{m}
$$

where $\sigma_{0}^{S}$ and $\sigma_{Y}^{S}$ denote the initial and the current yield strength of the material, $K$ is the hardening parameter, $m$ the hardening exponent and $\kappa^{s}$ the cumulative plastic strain in steel. A total-strain-based criterion is used to account for steel fracture, i.e. once the ultimate strain value, $\epsilon_{w}^{s}$, has been reached in tension or in compression in a layer, no stress can be developed in steel in that layer for any subsequent loading steps.

Stirrups are responsible for confining the concrete core of a RC member, i.e. for the generation of compressive transversal stresses in concrete. This motivates taking into account the multi-axial behaviour of concrete. An elasto-plastic behaviour is assumed for the concrete material with zero strength in tension, as in earlier works (Santafé Iribarren et al. 2011; Oliveira et al. 2014). Plasticity (irreversible deformation) is used to represent the bulk material degradation in compression by a softening behaviour, described by:

$$
\sigma_{Y}^{c}=\sigma_{0}^{c} \exp \left(h \kappa^{c}\right)
$$


where $\sigma_{0}^{c}$ and $\sigma_{Y}^{c}$ are the initial and the current yield strength of the material, $h<0$ is the softening parameter and $\kappa^{c}$ the cumulative compressive plastic strain measure in concrete.

A triaxial stress state is taken into account for concrete. The non-zero stress components are the compressive axial, in-plane and out-of plane transversal stresses, denoted as $\sigma_{x}^{c}, \sigma_{y}^{c}$ and $\sigma_{z}^{c}$, respectively. In the non-linear regime the stress tensor $\boldsymbol{\sigma}^{c}(\boldsymbol{\epsilon})$ is computed using a multidimensional yield surface. Various expressions for such

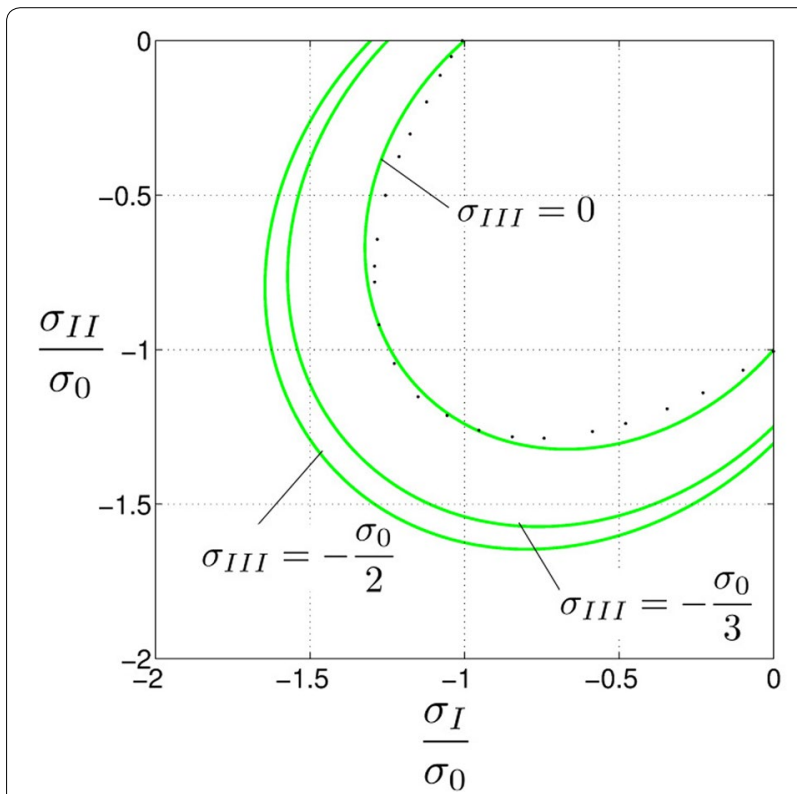

Fig. 2 Yield function evolution with the out-of-plane stress component (Eq. (7)), the black dots correspond to data reported in Comi (2001), obtained for plane stress. surfaces are available for concrete in the literature. Here, the yield criterion for concrete under multi-axial compression is inspired from Comi (2001) and reads:

$$
F_{y}\left(\sigma^{c}, \kappa^{c}\right)=a J_{2}+\alpha J_{1}^{2}+\beta J_{1}-\sigma_{Y}^{c}\left(\kappa^{c}\right)
$$

with $J_{1}[\mathrm{MPa}]$ and $J_{2}\left[\mathrm{MPa}^{2}\right]$ the first and second invariants of the stress tensor, respectively, and $\sigma_{Y}^{c}\left(\kappa^{c}\right)[\mathrm{MPa}]$ the current yield stress (Eq. (6)). $\alpha\left[\mathrm{MPa}^{-1}\right]$ and $\beta[-]$ are obtained by fitting the plane stress section of the yield surface to data presented in Comi (2001), and $a=1$ $\mathrm{MPa}^{-1}$ is a constant introduced for dimensional consistency. The evolution of the yield criterion as a function of the out-of-plane stress component is shown in Fig. 2 (with $\sigma_{I}, \sigma_{I I}, \sigma_{I I I}$ and $\sigma_{0}$ the principal stresses and the initial yield strength, respectively). As expected, the elastic domain is increased by the presence of the transversal compressive stress components.

\subsection{Concrete Ultimate Strain in Confined Concrete}

The ductility of reinforced concrete sections is known to critically depend on the compressive stress states. Practically, in the case of RC members this is reflected by their ultimate strain capacity being dependent on the presence and ratio of stirrups. In the layered beam model a stress-based plastic criterion alone cannot account for the increase of the ultimate strain in concrete in the confined core. As in the case of steel, a strain based criterion is employed here for the detection of full failure of concrete under compression. When the maximum longitudinal compressive total strain in concrete reaches the value of the ultimate strain, $\epsilon_{u}^{c}$, the concrete layer is considered as broken and no stress is carried by the material subsequently. For clarity, it is mentioned that the zero tension

(a)
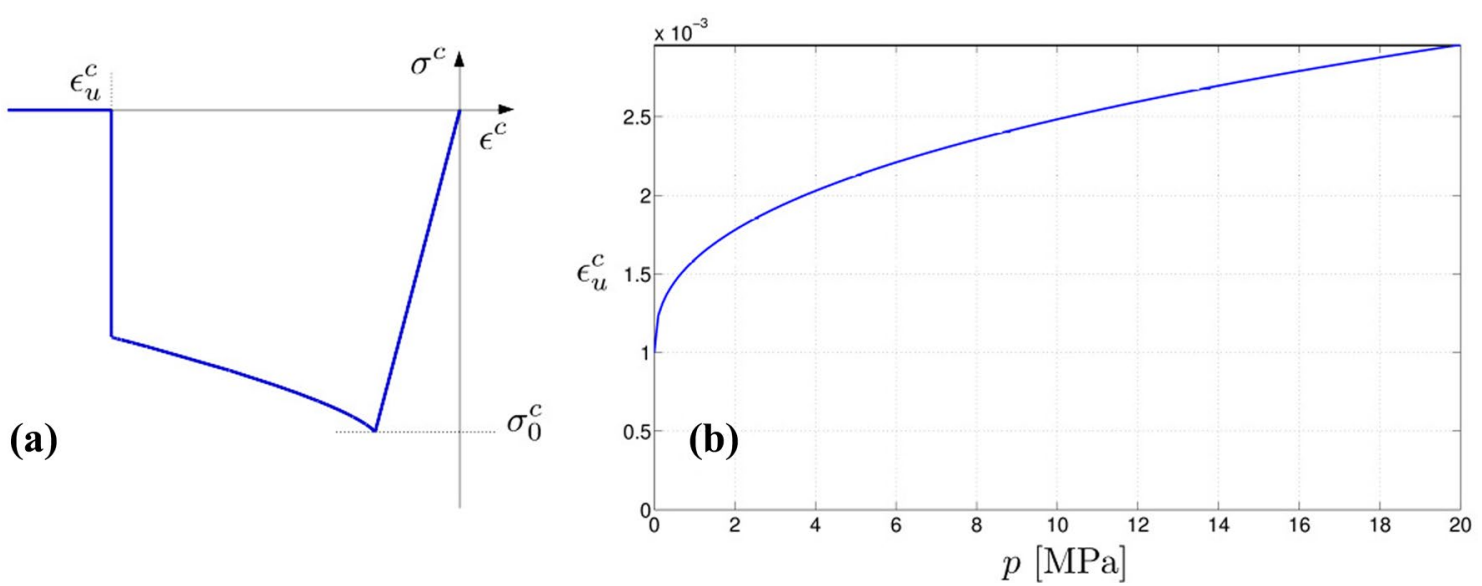

Fig. 3 a Unidimensional representation of the concrete constitutive model and $\mathbf{b}$ variation of the ultimate strain in concrete as a function of the hydrostatic pressure, according to Eq. (8) and the parameter set used in Sect. 3.2. 
assumption for concrete behaviour does not trigger this failure criterion in the model (Fig. 3).

Among the various contributions in the literature dedicated to compressive ductility of concrete, the experimental work of Imran and Pantazopoulou (1996) was taken as the basis for the relationship used here. The analysis of the data presented in Imran and Pantazopoulou (1996) shows a steep increase of concrete ultimate strain for low confining stress states followed by small subsequent variations for large confining stress states. Here, the following dependence of the ultimate strain of concrete, $\epsilon_{u}^{c}$, on the hydrostatic stress in concrete, $p=-\frac{\sigma_{x}^{c}+\sigma_{y}^{c}+\sigma_{z}^{c}}{3}$ is proposed:

$$
\epsilon_{u}^{c}=\epsilon_{u 0}^{c}+K p^{n}
$$

with $\epsilon_{u 0}^{c}$ the ultimate strain of concrete without confinement (e.g. from a uniaxial compression test), and with $K$ and $n$ material parameters to identify. The parameter $n$ influences the global shape of the $\epsilon_{u}^{c}(p)$ curve. A higher value of $n$ results in a $\epsilon_{u}^{c}(p)$ curve that reaches a plateaulike regime at higher hydrostatic pressure values and conversely, a lower value of $n$ produces a flatter curve. Variations in $n$ and the multiplier, $K$, have a low influence for low hydrostatic pressure values while the high hydrostatic pressure regime is more sensitive to them. A computational study showed that the sensitivity of the structural response to these material parameters depends also on the studied structure. Based on computational results, bending dominated cases are expected to be more sensitive to their variation than compression dominated ones. In this work $n=0.4$ is used, because it yields the best approximation of the data extracted from Imran and Pantazopoulou (1996). The multiplier, $K\left[\mathrm{MPa}^{-n}\right]$, can be estimated by fitting with experimentally available data, as illustrated in Sect. 3 using the experimentally measured structural response of reinforced concrete members with and without stirrups.

\subsection{Layerwise Transversal Equilibrium Formulation for Confined Concrete}

Although the transversal equilibrium equations used here are similar to the ones of Petrangeli et al. (1999), Mullapudi and Ayoub (2010), the numerical framework in which they are embedded is different.

First the kinematical assumptions are presented. The axial strain component in a given layer $i, \epsilon_{x}^{i}$ is directly computed from the displacement vector (Eq. (1)). A perfect adherence between steel and concrete is assumed, i.e. the axial and the transversal strains in the concrete core and in steel reinforcement are considered to be equal layerwise, leading to the following set of kinematical constraints for a given layer $i$ :

$$
\left\{\begin{array}{l}
\epsilon_{x}^{c i}=\epsilon_{x}^{s i}=\epsilon_{x}^{i} \\
\epsilon_{y}^{c i}=\epsilon_{y}^{s i}=\epsilon_{y}^{i} \\
\epsilon_{z}^{c i}=\epsilon_{z}^{s i}=\epsilon_{z}^{i}
\end{array}\right.
$$

This means that a constant value of strain is not enforced along the stirrups in the height of the cross section, i.e. strains can vary in a stepwise manner along stirrups when going from a layer to the next. While the adopted simplification does not reflect the real kinematics of the adherence between stirrups and concrete (possibly including micro-slip and debonding), it has been successfully used in numerical models (Petrangeli et al. 1999; Mullapudi and Ayoub 2010, 2013). It carries the advantage of a simple implementation because the strain (and stress) state of each layer is uncoupled from the behaviour of the neighbouring layers.

Equation (9) need to be complemented by equations ensuring transversal equilibrium involving the stresses in concrete and in steel in the confined core. Let us consider the in-plane transversal $(y)$ direction only for the equilibrium constraint (equations in the $z$ direction can be derived similarly). First, a geometrical variable expressing the stirrup area fraction in a smeared sense along the beam length is defined. The parameter $\Theta_{y}$ is defined as the ratio of the area in the $(x, z)$ plane of all of the stirrup steel bars, defined as $A_{(x, z)}^{s}$, to the area of confined concrete $A_{(x, z)}^{c c}$ in this plane. In layer $i$ the tension in stirrups equilibrates compressive transversal normal stress $\sigma_{y}^{c i}$ in concrete. The transversal equilibrium condition along $y$ is written as

$$
\sigma_{y}^{c i}\left(\epsilon_{i}\right)+\Theta_{y} \sigma_{y}^{s i}\left(\epsilon_{y}^{i}\right)=0
$$

in which the stress state along $y$ depends on the complete deformation state, $\boldsymbol{\epsilon}^{i}=\left\{\epsilon_{x}^{i}, \epsilon_{y}^{i}, \epsilon_{z}^{i}\right\}^{T}$. Considering the direction $z$ for layer $i$, it results in a second transversal stress equilibrium condition, similar to Eq. (10):

$$
\sigma_{z}^{c i}\left(\boldsymbol{\epsilon}_{i}\right)+\Theta_{z} \sigma_{z}^{s i}\left(\epsilon_{z}^{i}\right)=0
$$

with $\Theta_{z}=\frac{A_{(x, y)}^{s}}{A_{(x, y)}^{c c}}$. Since $\epsilon_{x}^{i}$ is given, the unknowns in Eqs. (10-11) expressed for layer $i$ are $\epsilon_{y}^{i}$ and $\epsilon_{z}^{i}$ that have to generate transversal stresses in steel and in concrete that satisfy the equilibrium constraints. The total number of transversal strain unknowns at an integration point of the beam with a confined concrete core section discretized into $n_{c}$ layers along the height is thus $2 \times n_{c}$. Note 
that in this model $\Theta_{y}$ and $\Theta_{z}$ are weighting factors of the stress in the steel stirrups that are fixed by the amount of reinforcement in the beam cross section.

The formulation implemented in this work shows similarity to the equilibrium constraint used for 2D beams in Petrangeli et al. (1999), Mullapudi and Ayoub (2010). However, as originality it includes the out-of plane transversal stress component as well, in a corotational framework. The corresponding system of equations is non-linear in the general case, since both materials exhibit a non-linear behaviour. The problem of finding the set of strains satisfying Eqs. (10) and (11) is solved using a Newton-Raphson iterative scheme on the level of a single layer, as explained in Sect. 2.6.

\subsection{Constant Out-of-Plane Strain Formulation for Confined Concrete}

This subsection is dedicated to a second possible formulation based on different kinematical assumptions. The layerwise equality of strain in concrete and steel in the in-plane transversal direction $y$ is maintained, but the same strain is assumed in the out-of-plane direction, $z$, for all of the confined concrete layers and stirrups. This new assumption avoids defining different out of plane strains for different layers along the height. The main equations of this formulation are as follows.

As earlier, a perfect adherence is assumed in the axial and in the in-plane transversal directions between concrete and steel, leading to the first two equations in Eq. (9). As opposed to the layerwise formulation (in which $\epsilon_{z}^{i}$ may be different in every layer discretizing the cross section in the $y$ direction), the strain along $z$ is assumed here to be the same in the whole confined concrete core, described by:

$$
\epsilon_{z}^{c i}=\epsilon_{z}^{s}=\epsilon_{z}
$$

The transversal equilibrium generated by stresses in concrete and in steel in the confined core is enforced by the satisfaction of a set of $n_{c}+1$ equations now, solved at the level of the confined core cross section discretized into $n_{c}$ layers.

$$
\left\{\begin{array}{l}
\sigma_{y}^{c i}\left(\epsilon^{i}\right)+\Theta_{y} \sigma_{y}^{s i}\left(\epsilon_{y}^{i}\right)=0 \\
\sum_{i=1}^{n_{c}} \sigma_{z}^{c i}\left(\epsilon^{i}\right) t^{i} s+A_{(x, y)}^{s} \sigma_{z}^{s}\left(\epsilon_{z}\right)=0
\end{array}\right.
$$

with $A_{(x, y)}^{s}$ the stirrup total cross-sectional area in the $(x, y)$ plane. $t^{i}$ and $s$ stand for the thickness of layer $i$ and the spacing of stirrups along the beam axis, respectively. For the sake of comparison with the out-of-plane stress equilibrium of the layerwise formulation, $\Phi_{z}=\frac{A_{(x, y)}^{s}}{s}$ can be used to rewrite the second equation in Eq. (13) as:

$$
\sum_{i=1}^{n_{\text {lay }}} \sigma_{z}^{c i}\left(\boldsymbol{\epsilon}^{i}\right) t^{i}+\Phi_{z} \sigma_{z}^{s}\left(\epsilon_{z}\right)=0
$$

Note that in Eq. (14) the effective concrete area that carries stresses in the out-of-plane direction is not assumed to be constant, the active zone in compression varies depending on the loading. The solution of the system of transversal equilibrium equations (Eq. (13)) involves the out-of-plane stress contributions from all of the $n_{c}$ layers in the confined core. Therefore a purely layerwise solution of the transversal equilibrium problem is no longer possible, as explained in the following.

\subsection{Numerical Solution of the Transversal Equilibrium Problems}

The requirement to satisfy transversal equilibrium conditions introduces an additional complexity requiring the nesting of the stress update procedures of the layers in an external iterative loop. In both stirrup formulations, a Newton-Raphson procedure is set up using the residual form of Eqs. (10-11) or (13). The solution algorithms for the unconfined layers and for both stirrup formulations are compared in Fig. 4.

In both stirrup formulations update of the transversal strain unknowns is performed in a two-step algorithm, starting with an elastic predictor that is computed using the assumption of a purely elastic increment starting from the last converged configuration. In case the resulting strain estimates lead to the violation of any of the yield functions (i.e. of concrete or of steel) in any of the layers, an iterative correction step is done. The plastification of both concrete, longitudinal reinforcements and stirrups is taken into account in the present models. For this, the construction of the tangent stiffness operator, corresponding to the derivative of the residuals with respect to the unknowns is necessary. This operator is defined as:

$$
K_{l w}=\left[\begin{array}{ll}
\frac{\partial r_{y}^{i}}{\partial \epsilon_{y}^{i}} & \frac{\partial r_{y}^{i}}{\partial \epsilon_{z}^{i}} \\
\frac{\partial r_{z}^{i}}{\partial \epsilon_{y}^{i}} & \frac{\partial r_{z}^{i}}{\partial \epsilon_{z}^{i}}
\end{array}\right]
$$

For the layerwise formulation $K_{l w}$ is a $(2 \times 2)$ matrix with $r_{y}^{i}$ and $r_{z}^{i}$ corresponding to the residual form of the equations (10) and (11), respectively. The terms in $K_{l w}$ depend on the tangent material stiffness of steel $(1 \times 1)$ and concrete $(3 \times 3)$ in layer $i$, that are natural by-products of 

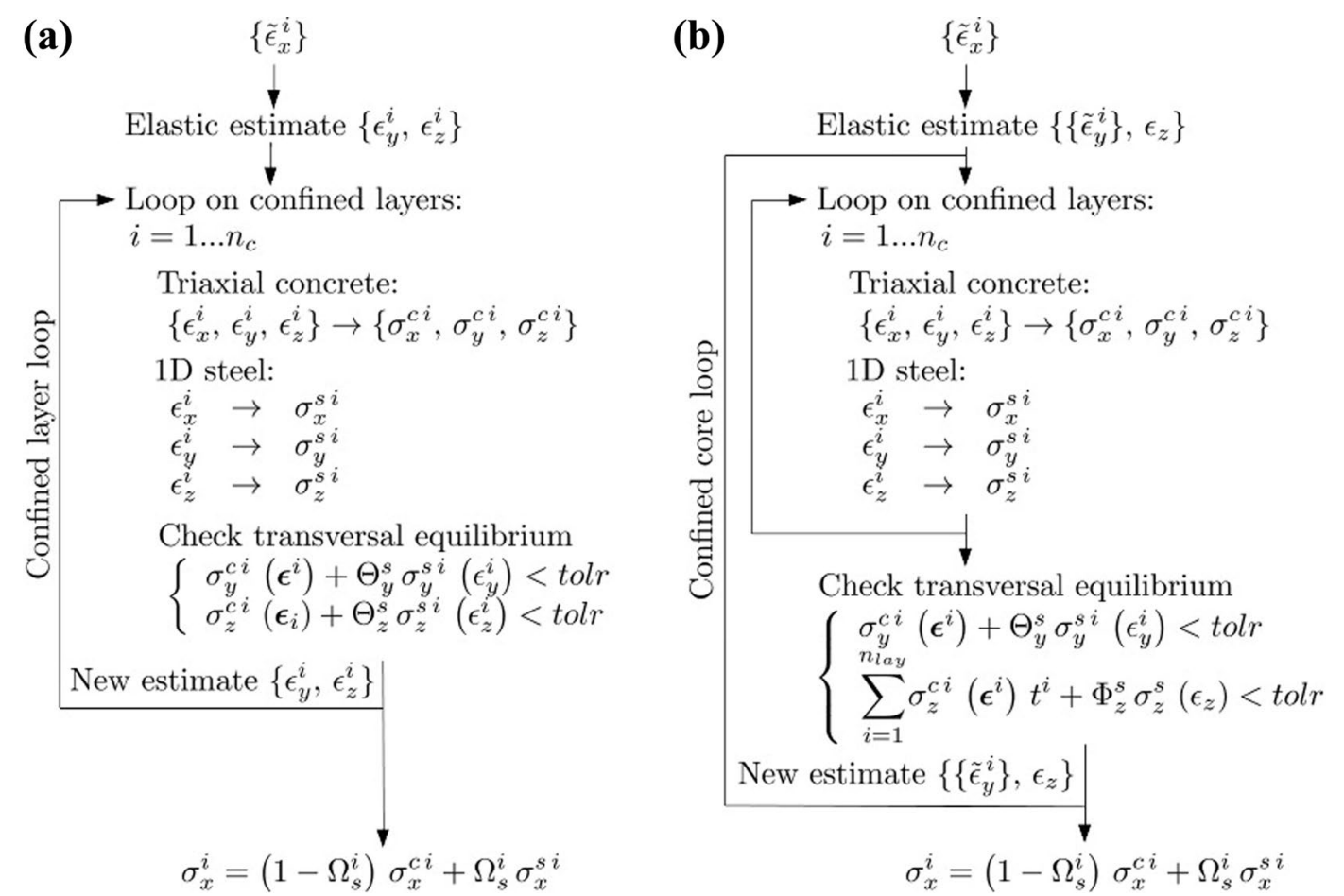

Fig. 4 Flowcharts of the solution algorithms used for $\mathbf{a}$ the black layerwise and $\mathbf{b}$ for the constant out-of-plane strain stirrup formulations with $\left\{\tilde{\epsilon}_{x}^{i}\right\}$ and $\left\{\tilde{\epsilon}_{y}^{i}\right\}$ the vector of axial and the in-plane transversal strains of the layers.

the return-mapping operations used for the update of stresses in these materials (Simo and Taylor 1985).

The size of the tangent stiffness operator for the constant out-of-plane formulation depends on the number of layers that constitute the confined core cross section, $n_{c}$. It reads:

$$
K_{\epsilon_{z}}=\left[\begin{array}{ll}
\frac{\partial \vec{R}_{y}}{\partial \vec{\epsilon}_{y}} & \frac{\partial \vec{R}_{y}}{\partial \epsilon_{z}} \\
\frac{\partial r_{z}}{\partial \vec{\epsilon}_{y}} & \frac{\partial r_{z}}{\partial \epsilon_{z}}
\end{array}\right]
$$

with $\quad \vec{R}_{y}=\left\{r_{y}^{1}, r_{y}^{2}, \ldots, r_{y}^{n_{c}}\right\}^{T}$, $\vec{\epsilon}_{y}=\left\{\epsilon_{y}^{1}, \epsilon_{y}^{2}, \ldots, \epsilon_{y}^{n_{c}}\right\}^{T}$ corresponding to the residual form of the set of in-plane transversal equilibrium equations in Eq. (13) and to the in-plane transversal strains in every layer in the confined core, respectively. $r_{z}$ denotes the residual form of the last equation in Eq. (13) and $\epsilon_{z}$ is the out-of-plane transversal strain common to all of the layers of the confined core. $K_{\epsilon_{z}}$ is thus an $\left(n_{c}+1\right) \times\left(n_{c}+1\right)$ matrix, with terms depending on the material tangent stiffness of concrete and steel.
Updating the axial stress components in every layer as explained above is required for the computation of the internal force vector of the finite element through Eqs. (2) and (3). The sectional stiffness required for the computation of the structural tangent stiffness matrix of the finite element depends on the axial material stiffness of each constituent in the layers through Eq. (4). The axial material stiffness of steel, $h_{x}^{s i}$, is directly obtained from the uniaxial return-mapping operations. The computation of $h_{x}^{c i}=\frac{\partial \sigma_{x}^{c i}}{\partial \epsilon_{x}^{i}}$ is more complex, as it involves an intrinsic coupling of all of the strain components through the transversal equilibrium equations. The concrete tangent stiffness in layer $i$ is obtained as:

$$
h_{x}^{c i}=\tilde{h}_{x x}^{c i}+\tilde{h}_{x y}^{c i} \frac{\partial \epsilon_{y}}{\partial \epsilon_{x}}+\tilde{h}_{x z}^{c i} \frac{\partial \epsilon_{z}}{\partial \epsilon_{x}}
$$

where $\tilde{h}_{i j}^{c}=\frac{\partial \sigma_{c i}}{\partial \epsilon_{j}}$ represents an element from the $(3 \times 3)$ material tangent stiffness matrix of concrete. The expressions of $\frac{\partial \epsilon_{y}}{\partial \epsilon_{x}}$ and $\frac{\partial \epsilon_{z}}{\partial \epsilon_{x}}$ can be derived through straightforward mathematical developments from the linearized 
version of Eqs. (11-10) and (13) for the layerwise and for the constant out-of-plane formulations, respectively.

\section{Assessment with Respect to Experimental Results}

This section is dedicated to the simulation of the experimental response of structural members reported in the literature. The performance of the proposed stirrup representations is assessed in terms of the strength and ductility enhancement effects and of the correlation to experimental results when available.

\subsection{Column Compression}

In this section a uniaxial compression test of a RC column is presented. The reinforcement scheme and the stirrup ratio are taken from experimental work (Lew et al. 2011). The column cross section is shown in Fig. 5. The stirrups are placed with a 4 inches interdistance along the axis of the column, considered to be 1 meter long. The material and geometrical parameters of the setup are given in Table 1. The Poisson ratio of concrete is taken as 0.2 in all simulations. The column is fixed at one end and the axial displacement of its other extremity is prescribed in a quasi-static simulation. A single beam finite element is used with 100 layers in the cross section. The structural response is computed (i) with no stirrups, (ii) with a layerwise stirrup representation (Sect. 2.4), and (iii) with a constant out-of-plane strain assumption (Sect. 2.5).
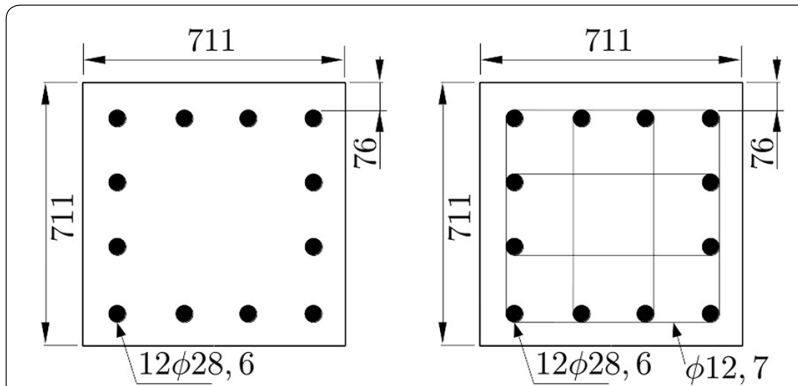

Fig. 5 Cross sections of the columns with and without strirrups used in Lew et al. (2011) (unit: mm).
For the sake of clarity, a first set of simulations attempts to uncouple the influence of stirrups on the strength enhancement and on the concrete ductility enhancement by artificially considering the same, constant ultimate strain in concrete for the cases with and without stirrups. This implies that concrete crushing occurs at the same axial displacement, independently of the presence of stirrups. The only effect on the structural response is in this case due to the axial stress level in concrete, which is expected to be higher due to the confinement effect when stirrups are present.

In Fig. 6, showing the axial reaction force vs. axial displacement curves, the first linear elastic phase is followed by a plastic plateau when stirrups are not considered. The reaction force remains practically constant from 2.8 $\mathrm{mm}$ axial displacement until concrete failure, shown by the sudden decrease in the reaction force at $5.3 \mathrm{~mm}$ axial displacement. The almost constant normal force in the column without stirrups is explained by a sectional level balance between the exponential softening behaviour of concrete and the non-linear hardening behaviour of steel in the uniaxial constitutive laws of the layers. Concrete fails in crushing when its ultimate strain $\left(\epsilon_{u}^{c}=0.0053\right)$ is reached and only the steel reinforcement then contributes to the axial reaction force from this point on. Due to the uniaxial loading condition concrete failure occurs simultaneously in all layers, which also corresponds to the final structural failure. At $5.3 \mathrm{~mm}$ axial displacement

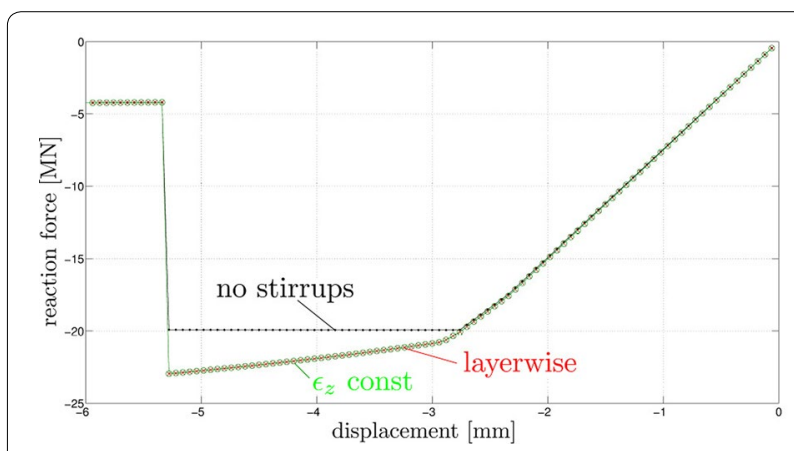

Fig. 6 Reaction force vs. displacement curves of the column compression with constant concrete ultimate strain $\epsilon_{u}^{c}=0.0053$.

Table 1 Model parameters used in the column compression and beam bending simulations when $\epsilon_{u}^{c}$ depends on the hydrostatic stress.

\begin{tabular}{llllllll}
\hline $\mathrm{E}^{\boldsymbol{s}}(\mathrm{GPa})$ & $\boldsymbol{\sigma}_{0}^{\boldsymbol{s}}(\mathrm{MPa})$ & $\boldsymbol{K}(\mathrm{MPa})$ & $\boldsymbol{m}$ & $\boldsymbol{\epsilon}_{\boldsymbol{u}}^{s}$ & $\boldsymbol{\Theta}_{\boldsymbol{y}}$ & $\boldsymbol{\Theta}_{\boldsymbol{z}}$ & $\boldsymbol{\Phi}_{\boldsymbol{z}}(\mathrm{m})$ \\
\hline 200 & 469 & 250 & 0.1 & 0.14 & 0.00899 & 0.00899 & 0.00498 \\
\hline $\mathrm{E}^{\boldsymbol{c}}(\mathrm{GPa})$ & $\boldsymbol{\sigma}_{0}^{c}(\mathbf{M P a})$ & $\boldsymbol{\alpha}(\mathbf{1} / \mathrm{MPa})$ & $\boldsymbol{\beta}$ & $\boldsymbol{h}_{\boldsymbol{c}}$ & $\boldsymbol{\epsilon}_{\boldsymbol{u} 0}^{c}$ & $\boldsymbol{k}$ & $\boldsymbol{n}$ \\
\hline 27 & 32 & 0.0962 & 12.7435 & -5 & 0.0035 & 0.00062 & 0.4 \\
\hline
\end{tabular}

For the column compression, some simulations with constant concrete ultimate strain were performed with $\epsilon_{u}^{c}=0.0053$. 
the reaction force suddenly drops from 19.9 to $4.2 \mathrm{MN}$ due to concrete crushing.

As expected, in the presence of stirrups the concrete crushing occurs at the same axial displacement, since the same concrete ultimate strain is used. Both implemented stirrup models yield the same structural response, since in uniaxial compression all strain and stress components remain homogeneous in the confined concrete volume (Fig. 7), and both transversal equilibrium conditions result in the same stress state. Differences in the sectional response between the two stirrup models are expected only when strain and stress gradients appear in the confined concrete volume (e.g. in the case of bending in Sect. 3.2). The main differences with respect to the case without stirrups are the higher reaction force in the plastic response resulting from the confinement effect of stirrups and their monotonous increase until concrete crushing. The peak reaction force with stirrups is close to $23 \mathrm{MN}, 15 \%$ higher than in the case without stirrups. In fact, considering the monotonous increase in the reaction force when stirrups are considered the difference between the peak load with and without stirrups is expected to grow if the concrete ultimate strain is increased.

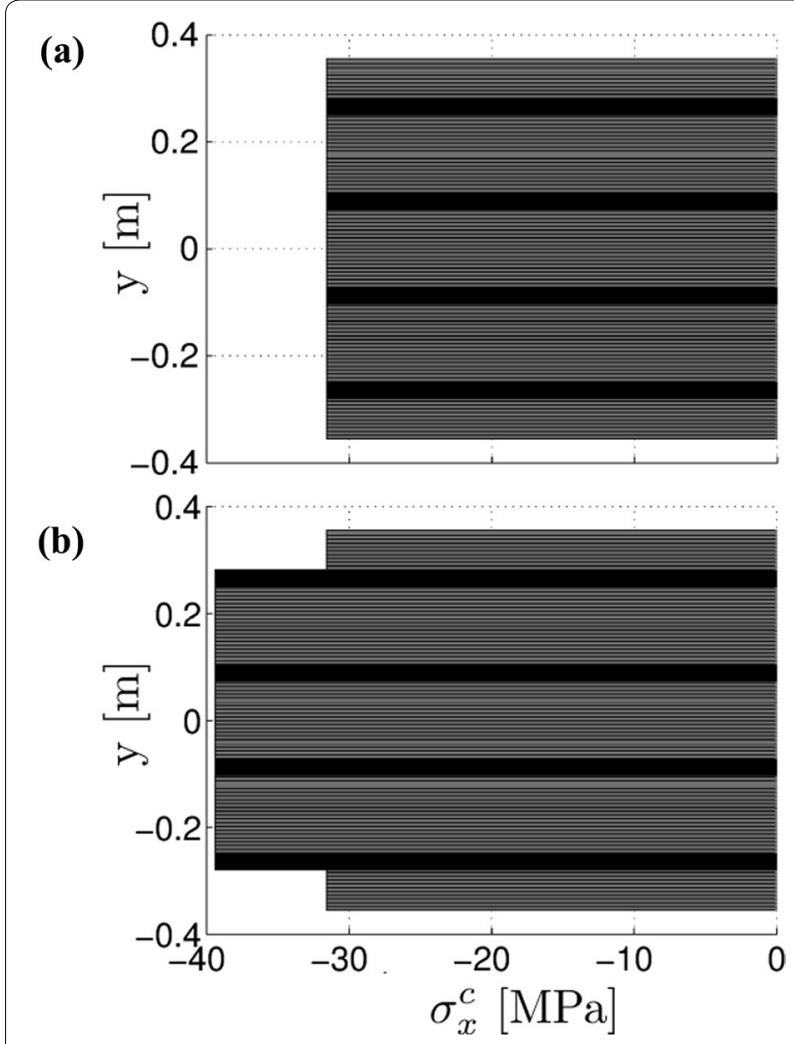

Fig. 7 Axial stress distribution in concrete at peak load for constant $\epsilon_{u}^{c}=0.0053$, a without stirrups and $\mathbf{b}$ considering stirrups, with axial reinforcements shown in black.
At peak reaction force the axial stress level in concrete is $-31.6 \mathrm{MPa}$ in the unconfined layers and $-39.4 \mathrm{MPa}$ in the confined concrete layers (24.6\% relative increase), as shown in Fig. 7. This higher axial stress level in the confined concrete core can be reached due to the $-3.9 \mathrm{MPa}$ transversal confining stresses (same in both transversal directions because the stirrup ratio is the same).

In a second step, the ultimate strain in concrete is set to be dependent on the hydrostatic stress in the confined concrete layers through Eq. (8) with an initial concrete ultimate strain of $\epsilon_{u 0}^{c}=0.0035$. This corresponds to a standard value for concrete without confinement effects. The material parameters appearing in Eq. (8) are close to the ones in Sect. 3.2, fitted to experimental data. As expected, the structural response without stirrups only differs from the previous case by exhibiting concrete crushing at lower axial displacement due to the decrease of the ultimate strain in concrete from 0.0053 to 0.0035 (Fig. 8). As earlier, and for the same reasons of a homogeneous stress state in the confined concrete core, the response of both stirrup models is practically identical. The reaction force vs. displacement curves of models with stirrups show a first sudden drop in the reaction force at $3.5 \mathrm{~mm}$ axial displacement, which corresponds to the crushing of the non confined concrete cover. This is followed by a monotonous increase in the reaction force until crushing of the confined layers occurs at $5.3 \mathrm{~mm}$ axial displacement (relative increase of over $50 \%$ with respect to the case without stirrups). The area under the reaction force vs. displacement curves is proportional to the dissipated energy due to plastic straining of concrete and steel in the column. Due to the higher reaction forces and later concrete crushing in the confined core a significant relative increase of $84.5 \%$ is obtained in the energy dissipated until structural failure with respect to the case without stirrups.

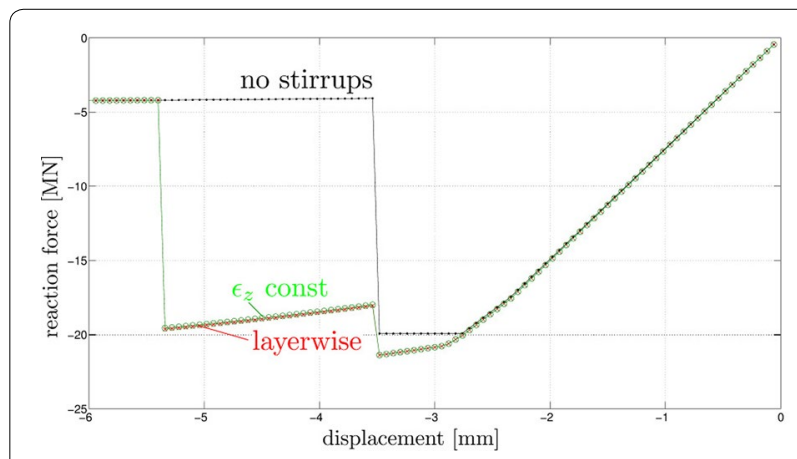

Fig. 8 Reaction force vs. displacement curves of the column compression with the concrete ultimate strain being function of the hydrostatic pressure. 


\subsection{Numerical-Experimental Correlation in a Four-Point Bending Test}

In this section a direct qualitative and quantitative comparison is presented between numerical results and experimental data of a displacement controlled four point bending test investigating the influence of stirrups on the structural behaviour. In the experimental work reported in Biolzi et al. (2014), several beams have been tested, either with a cross section including bottom reinforcements only or with a cross section with top and bottom reinforcements and stirrups. The beam cross sections considered in this study (Biolzi et al. 2014) and used here are shown in Fig. 9 together with the boundary conditions applied in the numerical model. The structure is discretized into 14 finite elements with 100 layers in the cross section. In the quasi-static simulations the vertical displacement of points $f$ and $g$ shown in Fig. 9 is prescribed.When present, the stirrups are placed at an interdistance of 15 centimetres along the axis of the

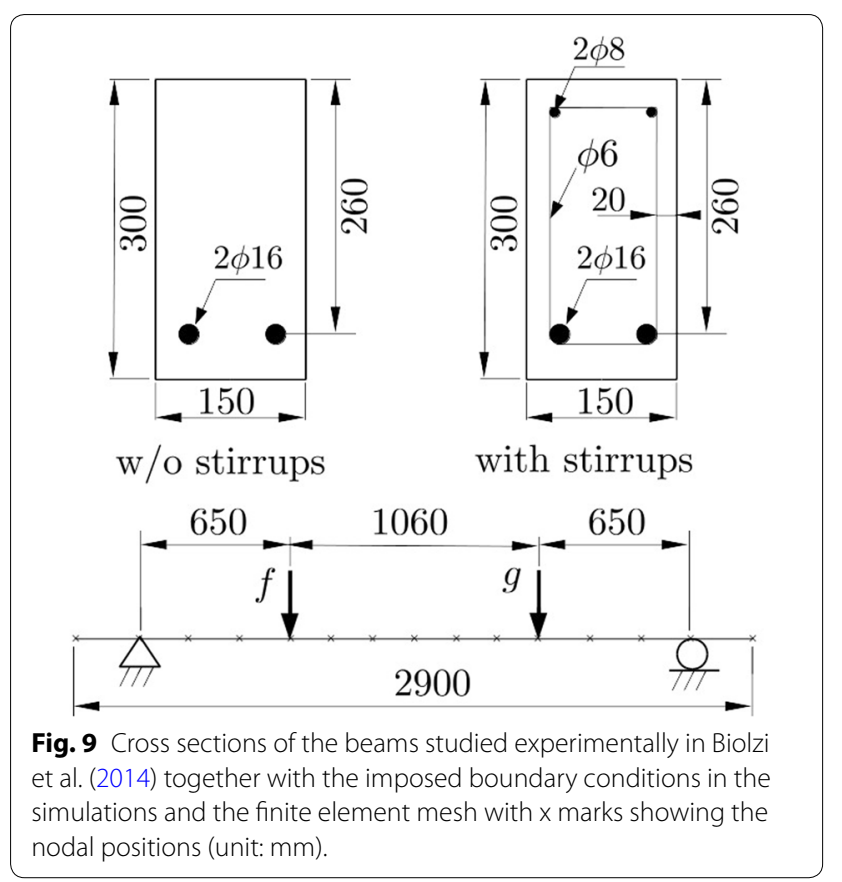

beam. The corresponding geometrical properties of the sections with stirrups are described by the parameters $\Theta_{y}=0.00344, \Theta_{z}=0.00160$ and $\Phi_{z}=0.00038 \mathrm{~m}$. Different beams made of three different concrete grades were considered in the experimental work, referred to as concrete with 40, 75 and $90 \mathrm{MPa}$ nominal compressive yield limit (Biolzi et al. 2014). The material parameters used in simulations for these concretes and steel are given in Table 2.

While several of the material parameters have been measured in Biolzi et al. (2014), such as the elastic modulus and yield strength of steel and of the three concrete grades, the parameters governing the ultimate strain in concrete needed to be determined. The ultimate strain of concrete without confinement effects, $\epsilon_{u 0}^{c}$, was identified in order to have a good match between the experimental and the numerical load vs. displacement curves without stirrups. Its value was observed to be the lowest for concrete with a $90 \mathrm{MPa}$ nominal compressive yield strength. The ultimate concrete strain parameter, $K=0.00059$, was identified by matching the computationally obtained load-displacement curve for the $40 \mathrm{MPa}$ concrete with stirrups with the experimental data, using the previously determined $\epsilon_{u 0}^{c}$ and $n=0.4$. $K$ and $n$ were subsequently kept the same in the simulations for other grades of concrete. A physically acceptable steel ultimate strain of over $10 \%$ was assumed.

The experimental failure mode of all studied beams involved systematically concrete crushing on the top of the beams at mid-span and the initiation of the beam failure occurred at less than $3 \%$ of axial strain in tension in the reinforcements, therefore no fine tuning of the steel ultimate strain parameter was required. The softening parameter for concrete was kept $h=-5$, corresponding to a slight softening, as in Oliveira (2015).

The applied load vs. mid-span vertical displacement curves issued from simulations are plotted on top of the experimental data in Fig. 10. The following main observations can be made on these curves: (i) all beams without stirrups exhibit a brittle behaviour with an early failure and a steep decrease in the reaction forces, (ii) all beams with stirrups have a significantly more ductile response

Table 2 Material properties for steel and for the three concrete grades used in the four point bending simulations.

\begin{tabular}{|c|c|c|c|c|c|}
\hline & $\mathrm{E}^{s}(\mathrm{GPa})$ & $\sigma_{0}^{s}(\mathrm{MPa})$ & $K(\mathrm{MPa})$ & $m$ & $\epsilon_{u}^{s}$ \\
\hline \multirow[t]{2}{*}{ Steel } & 200 & 516.5 & 1.445 & 1 & 0.15 \\
\hline & $\mathrm{E}^{c}(\mathrm{GPa})$ & $\sigma_{0}^{c}(\mathrm{MPa})$ & $\alpha(1 / \mathrm{MPa})$ & $\beta$ & $\epsilon_{u 0}^{c}$ \\
\hline $40 \mathrm{MPa}$ & 37.4 & 55.47 & 0.1099 & 23.5574 & 0.0010 \\
\hline $75 \mathrm{MPa}$ & 39.2 & 74.56 & 0.1111 & 32.1400 & 0.0010 \\
\hline $90 \mathrm{MPa}$ & 41.5 & 81.61 & 0.1113 & 35.2978 & 0.0007 \\
\hline
\end{tabular}




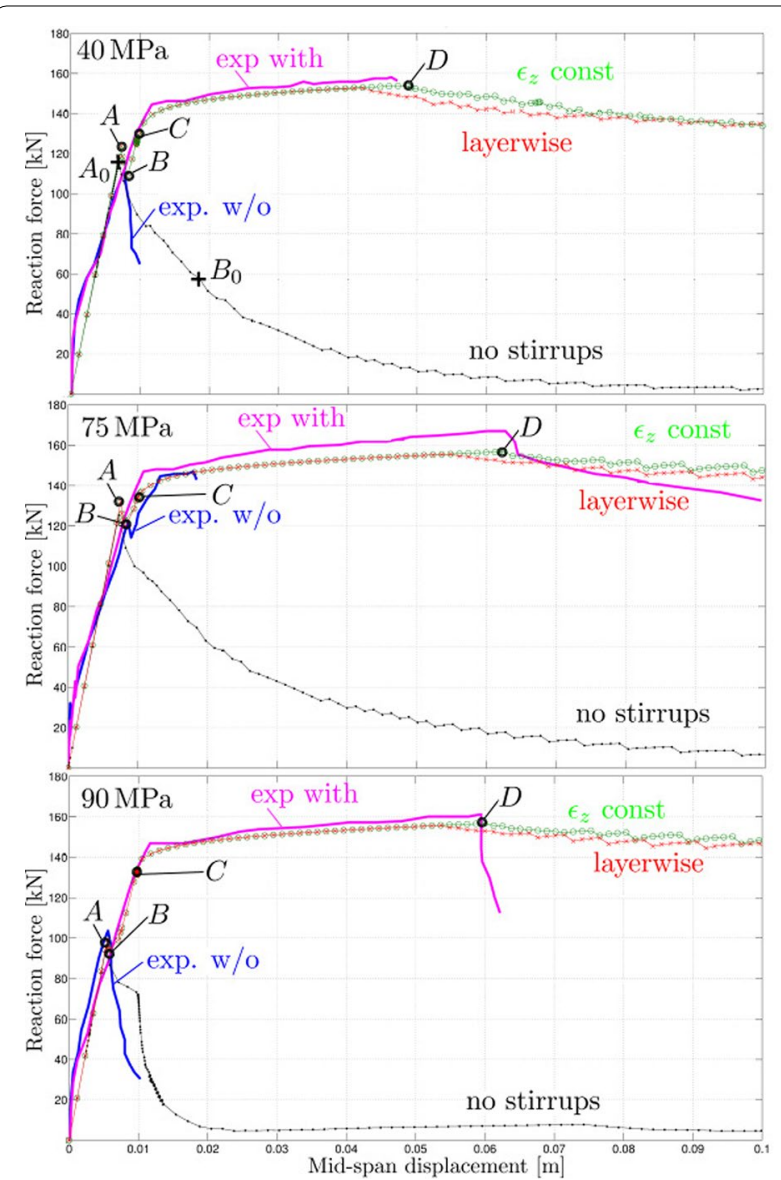

Fig. 10 Reaction force vs. mid-span vertical displacement curves for setups with different concrete grades with and without stirrups and experimental data shown in thick solid lines.

forming a long plateau at a roughly constant reaction force before final failure, (iii) the force level of this plateau is similar for all three concrete grades and (iv) the mid-span vertical displacement at failure is the highest for the $75 \mathrm{MPa}$ concrete and lowest for the $40 \mathrm{MPa}$ concrete grades.

Using a parameter set with the majority of the material parameters taken from measurements in Biolzi et al. (2014), the computed structural behaviour for all six considered cases matches well the experimental data, both in terms of load vs. displacement curves and failure mechanism.

First, the response of the numerical beam models without stirrups are examined. All three beams with different concretes exhibit a similar structural behaviour characterized by a single peak in the reaction force (shown by point $A_{0}$ in Fig. 10 only for the $40 \mathrm{MPa}$ grade concrete for the sake of good visibility), followed by a steep, monotonous decrease leading to failure by concrete crushing. The slightly lower structural stiffness in the simulations at the start of the loading is potentially due to the zero tension assumption in concrete. The post-peak steep decrease in the reaction force is explained by the continuous progression of failure of the concrete layers in compression starting from the top of the section. The main material parameter controlling the start of failure is thus the ultimate strain in concrete. The single case presenting a discrepancy is the $75 \mathrm{MPa}$ concrete grade, where experimentally a significantly more ductile structural behaviour, similar to the one of beams with stirrups (formation of a plateau at constant reaction force level) was observed. This corresponds to an unexpected structural response that cannot be explained based on the simulations.

Indeed, no mechanism potentially responsible for an increase in the reaction force after the initiation of gradual concrete crushing could be identified in the case of beams without top reinforcements and stirrups.

The structural response of beams using the layerwise and the constant out-of-plane strain stirrup formulations in the simulations are next examined. As observed in the experiments, the structural behaviour with stirrups is similar and the structural failure by concrete crushing is obtained for all three concrete grades. The common characteristics when considering stirrups are a much higher ductility of the structure (the deflection at failure is multiplied by a factor of 5) and the presence of a plateau at a force level almost independent from the concrete grade. Particular points in the structural response allowing for a deeper insight into the evolution to structural failure ( $A$ to $D$ ) are highlighted in Fig. 10. Note that even though the position of these points may vary as a function of the concrete grade, the same corresponding phenomena are present in all responses with stirrups. Point $A$ is the first peak in the reaction force, corresponding to the initiation of the crushing of the concrete cover. The top concrete cover is fully failed by crushing at point $B$, as illustrated in Fig. 11 showing sectional longitudinal normal stress distribution at mid-span for point $B$. The crushing of the concrete cover is of brittle nature and results in a steep decrease in the reaction forces. This first peak is not apparent in the experimental load-displacement curves, potentially because of the more gradual nature of concrete crushing in a real life test than its layerwise numerical representation.

Between points $B$ and $C$ the reaction force is monotonously increasing with a slope similar to the experimental one. On the sectional level, the stress in the confined concrete core and in the steel reinforcements is increasing with the top reinforcements already working in the plastic regime. Point $C$ is the start of a visible decrease in the tangent of the load-displacement curve. This corresponds to the start of the plastic response of the whole 

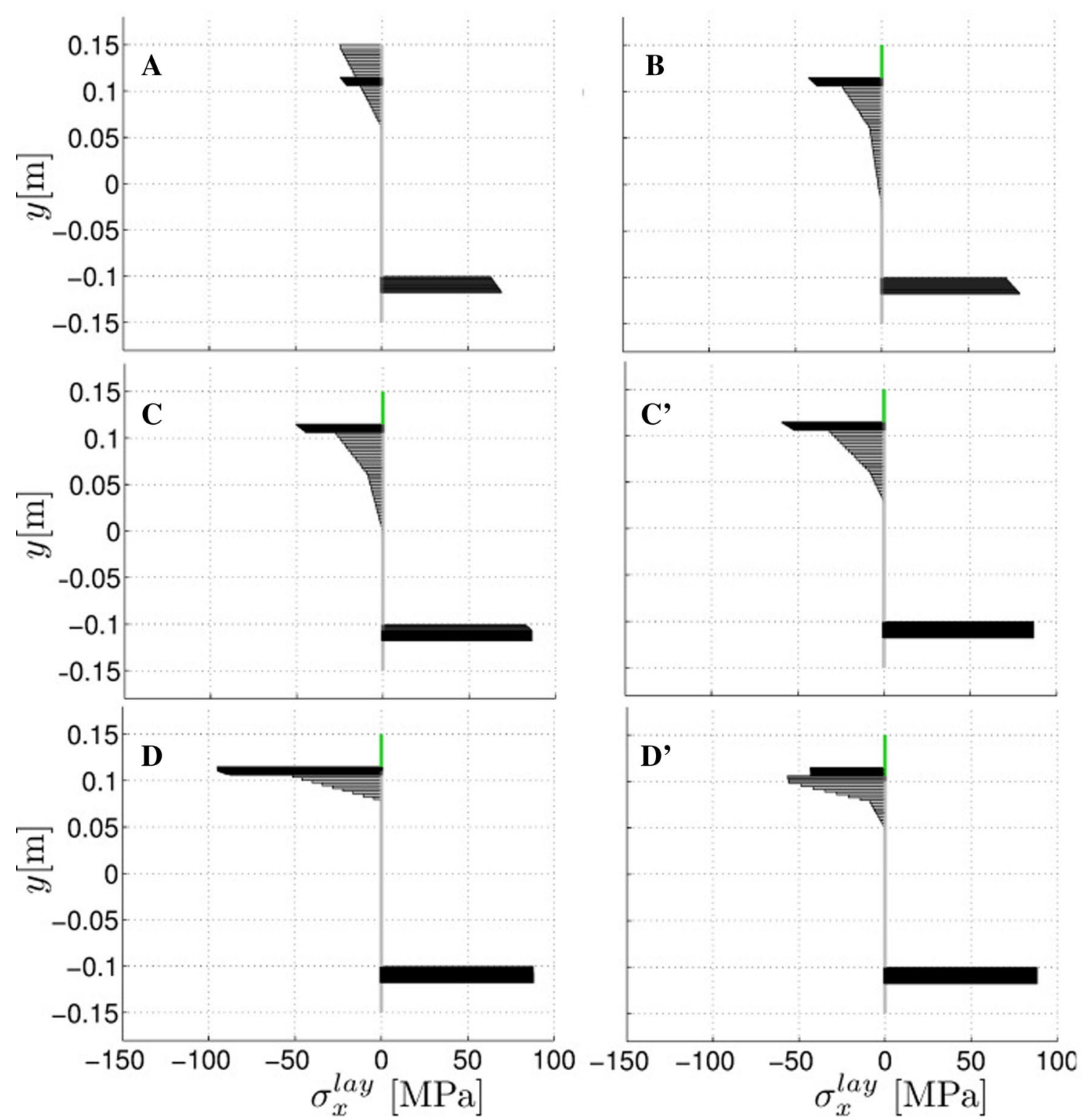

Fig. 11 Composite axial stress distribution close to mid-span at points $A$ to $D$ in Fig. 10 with crushed concrete layers and plastic steel shown in green and black, respectively.

cross section, i.e. including the bottom reinforcement in tension. Figure $C^{\prime}$ in Fig. 11 shows that all the layers that discretize the cross section of the bottom reinforcement are plastic (black colour) in the increment directly following point $C$.

Between points $C$ and $D$ the reaction forces of the structure evolve smoothly, their magnitude being governed by the axial behaviour of confined concrete and the hardening behaviour of the top and bottom steel reinforcements. The number of layers developing stresses in the cross section varies smoothly and no additional layers fail until point $D$ is reached.

Point $D$ in Fig. 10 corresponds to the initiation of the crushing of the confined core in the numerical model. It matches the final drop in the experimental load-displacement curves associated to a concrete crushing failure mode. In the simulations point $D$ is the last increment in which all the layers in the confined concrete core are unbroken, i.e. in the following increments a gradual failure of confined concrete layers by crushing propagates from the top reinforcement to the bottom (point D' in 
Fig. 11). As opposed to the experimental observation, in the numerical model this results in a gradual decrease of the reaction force instead of a large drop. This can be explained by the simplified modelling that does not reproduce the breakdown of the confinement conditions in the concrete core when cracks penetrate it. Such effects are very complex to tackle using a layered beam formulation. Experimentally, this phenomenon can result in various structural responses, potentially depending on the material microstructure of concrete and the generated complex local stress states around the cracks. In the experimental work (Biolzi et al. 2014), both a strong drop in the reaction forces (90 MPa concrete grade) and a more ductile structural response $(75 \mathrm{MPa}$ concrete grade) were observed. Therefore, even though no "sudden" structural failure shown by a drop in the reaction force appears in the numerical load-displacement curves at point $D$, it can be considered as the last increment before initiating structural collapse.

Both numerical formulations for stirrups show a similar structural response. The main difference is the magnitude of the vertical mid-span displacement at point $D$. The layerwise stirrup formulation predicts a slightly earlier failure than the formulation based on the constant out-of-plane strain assumption. This can be explained by the difference in the ultimate strain of the confined concrete layers (Fig. 12) as a result of different stress states in the models. At point $D$ the in-plane transversal stress component gives close values in both stirrup formulations (in the order of some tenth of $\mathrm{MPa}$ to $1 \mathrm{MPa}$ ) but the out-of plane transversal stress is significantly higher in the constant out-of-plane strain (around 9.5-10 MPa) than in the layerwise formulation (some tenth of $\mathrm{MPa}$ ). This is a natural outcome of the fact that in this formulation only the concrete layers in compression carry stresses that equilibrate the force generated in the out-ofplane direction by the steel stirrup. The result generally is a smaller effective area (and its evolution) over which concrete stresses can act in the $z$ direction, compared to the layerwise formulation. Because of the nature of the considered concrete yield surface a higher value of the confining stress allows for the development of a higher axial stress. The increased capacity of the confined concrete layers to carry stress results in the development of a higher hydrostatic stress, which influences beneficially the ultimate strain of confined concrete. Considering the experimentally-inspired asymptotic nature of the increase in concrete ultimate strain as a function of the confining hydrostatic stress, the peak value of ultimate strain at point $D$ remains close in both stirrup formulations, as shown in Fig. 12. On the other hand, this particular test was observed to be extremely sensitive to the ultimate strain in concrete, therefore even a small variation in its value is apparent in the load-displacement curves.

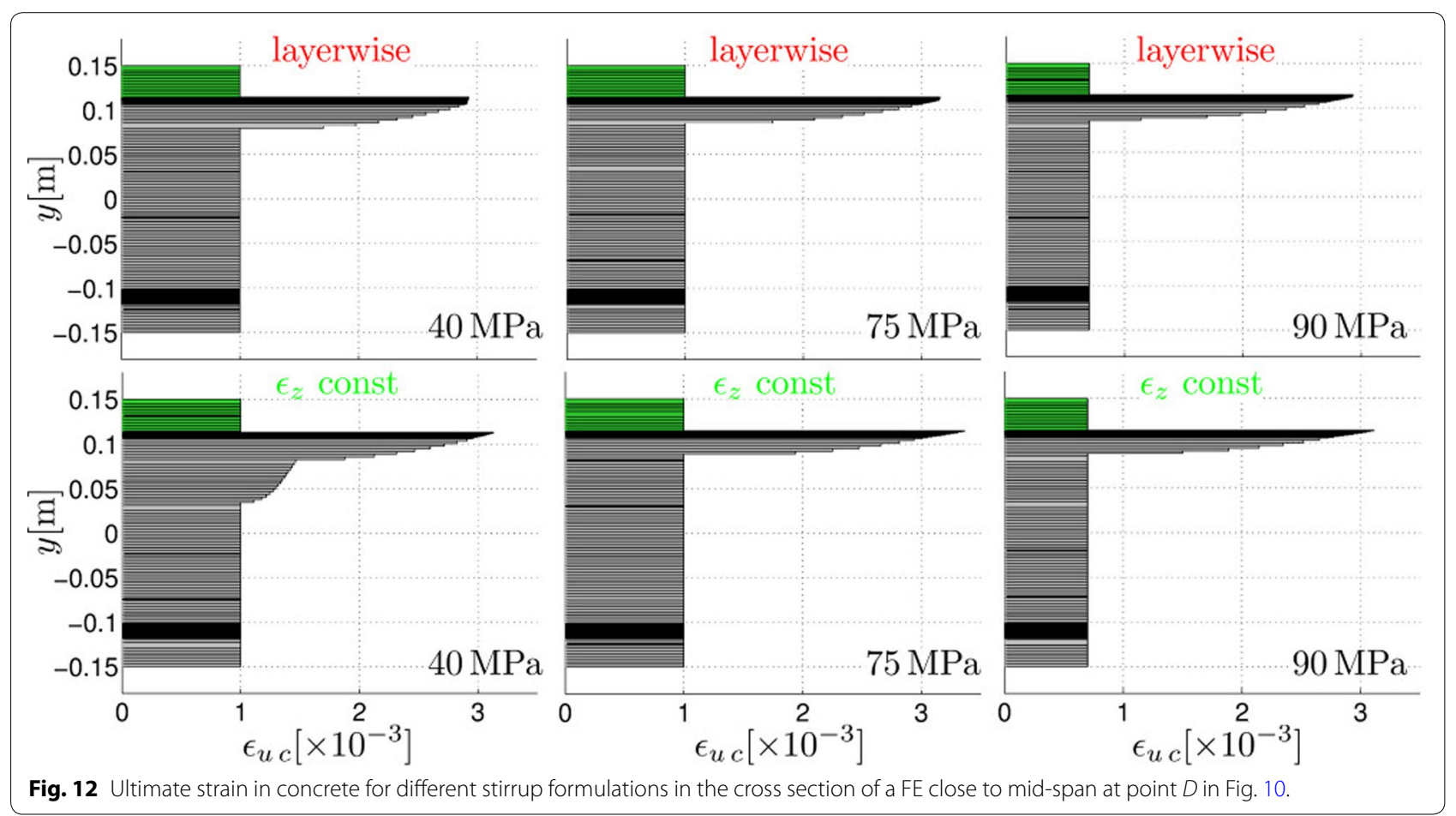


Note that the stirrups generating compressive confinement were observed to remain elastic, with stresses in tension reaching peak values over $300 \mathrm{MPa}$ with both stirrup models.

The vertical displacement at mid-span at structural failure matches best the experimental values with the constant out-of-plane strain stirrup formulation. The general trend is that a higher initial yield strength in concrete leads to a larger increase in the vertical displacement at failure (point $D$ ) when stirrups are considered, because the capacity to develop higher stresses in the material (both in the axial and transversal directions) influences beneficially the concrete ultimate strain. The reason why the vertical displacement at failure is close for 75 and $90 \mathrm{MPa}$ concrete grades is that the initial ultimate strain in concrete was taken lower for the $90 \mathrm{MPa}$ concrete (Table 2), based on the fit performed on the load-displacement curves without stirrups.

Note that the layerwise formulation also gives a good, but somewhat lower estimation to the vertical displacement at failure, with the same trends.

With the adopted Bernoulli beam assumption the reaction forces/moments are generated by the axial stress component in the layers. An explanation for having very similar force levels between points $C$ and $D$ in the load versus displacement curves when using different concrete grades can be given based on the axial stress distribution in concrete in the beam cross section (Fig. 13). As expected, the stress levels are higher when concrete with a higher initial yield strength is considered. The reason why the structural response is practically the same for the three concrete grades, even though the axial stress levels are different, stems from their distribution in the cross section. For the $40 \mathrm{MPa}$ concrete grade the axial stress distribution in the layerwise formulation takes a low peak stress value $(-56.6 \mathrm{MPa})$ with a larger compressed zone (i.e. in more layers). Conversely the $90 \mathrm{MPa}$ concrete stress distribution has a higher peak stress $(-82.5 \mathrm{MPa})$ on a smaller number of layers. The integration (finite summation) of these different axial stress contributions in the cross section results in similar generalized stresses on the sectional level.

It is worth mentioning that in all examples above the axial stress in confined concrete reached higher values than the uniaxial yield strength although a softening behaviour is considered (up to $12 \%$ higher at point $D$ for $90 \mathrm{MPa}$ concrete grade and the constant out-of-plane strain formulation) due to the multi-dimensional stress state in concrete.

\section{Discussion}

The formulations developed in this contribution perform well in the structural computations in capturing the experimentally observed effects of stirrups on the strength and ultimate strain of confined concrete. The uniaxial compression of a column corresponds to a limit case in which the influence of stirrups is maximized,

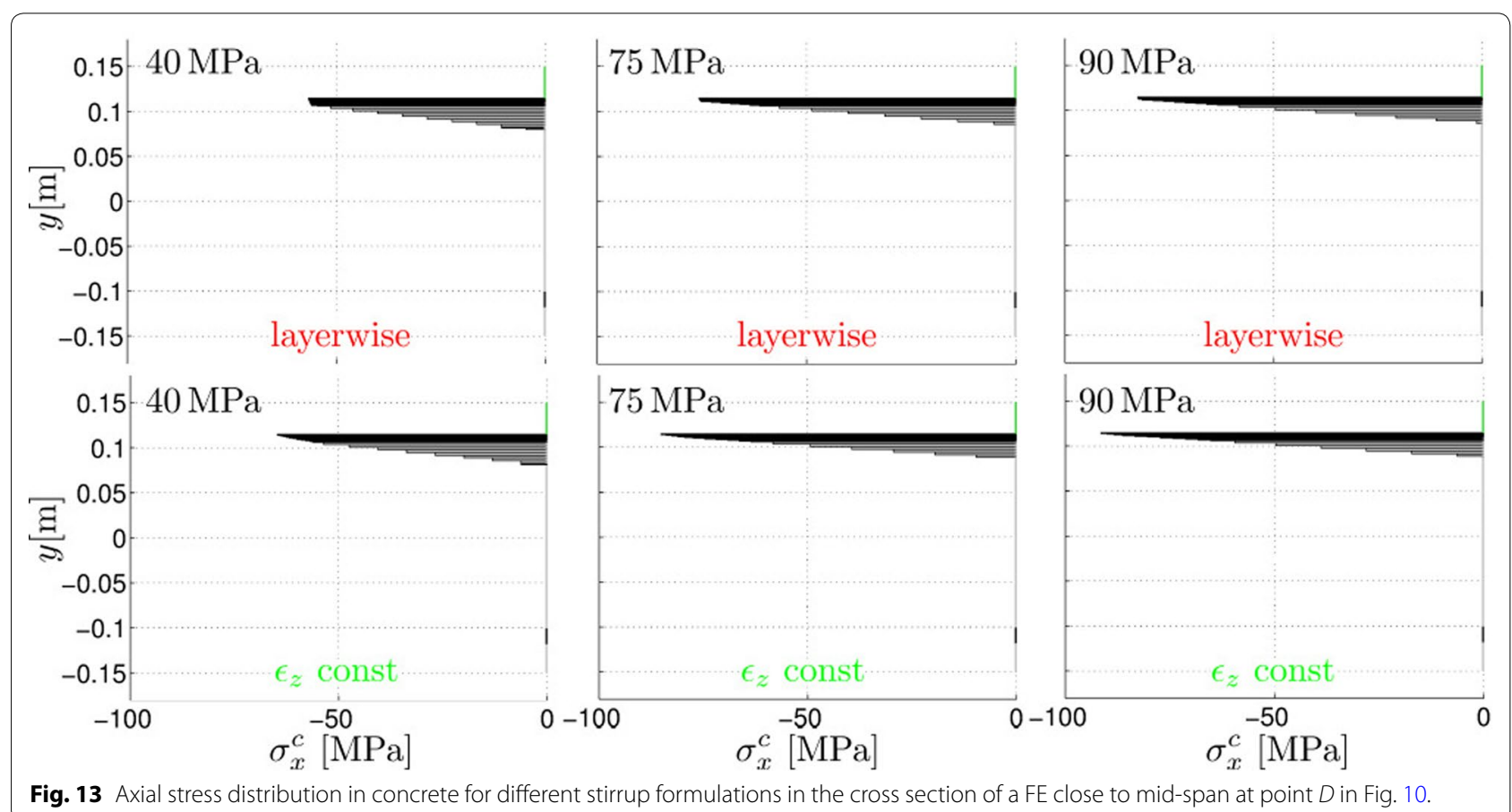


since the increase in peak concrete axial stress and in ultimate strain due to confinement is present in all layers of the confined core. The good agreement with experimental data in Sect. 3.2 shows that the numerical models remain valid for more complex stress distributions in the beam cross section. The impact of the simplifying assumptions used in the simulations is discussed here.

Even though the structural response of both stirrup formulations are close to each other, the local stress state in the confined concrete layers are quite different. The out-of plane transversal stress component can be up to an order of magnitude lower in the case of the layerwise with respect to the constant out-of-plane strain stirrup formulation in the same increment. In Eq. (11) the total concrete core projected cross section (which are usually similar in both transversal directions) is used as area on which the confined concrete's stresses counteract the forces generated in the steel stirrups. The layerwise transversal equilibrium conditions and kinematic ties in the $y$ and $z$ directions are similar, leading to stresses in the inplane and in the out-of-plane transversal directions of the same order of magnitude. In the equilibrium equation of the constant out-of-plane strain condition the effective concrete area that carries stresses in the out-of-plane direction is not assumed to be constant. It corresponds to the cross-sectional area formed by the layers in compression in this model, which can be small compared to the total concrete core's cross-sectional area in some relevant practical loading cases. Which one of these simplifying modelling assumptions for stirrups and resulting stress states in confined concrete is more realistic should be further investigated in future work, possibly linking it to experimental measurements or full 3D simulations.

Depending on the application the variation of the ultimate strain of confined concrete can be dominant on the structural response (Sects. 3.1 and 3.2) or less important. This depends on the final structural failure mode and, in cases where concrete crushing is a dominant feature in the failure evolution, the parameters $\epsilon_{u 0}^{c}, K$ in Eq. (8) should be determined carefully. Maintaining $n=0.4$ is proposed, since the resulting relationship reflects well the experimentally observed first rapid, than gradual variation in the ultimate strain as a function of increasing hydrostatic stress (Imran and Pantazopoulou 1996). Solving the additional transversal equilibrium constraints obviously results in an increase in computational time compared to the model using uniaxial material representations only: up to 1.5 and 2.5 times for the layerwise and the constant out-of-plane strain formulations, respectively.

The layerwise stirrup formulation is computationally cheaper, because local iterations are performed separately for each layer. The number of operations depends on the degree of non-linearity of the single layer problem. In the constant out-of-plane strain stirrup formulation, iterations are required on the confined core level when only a few fibres exhibit a non-linear behaviour (Fig. 4b).

\section{Conclusion and Perspectives}

This contribution presented two numerical formulations for a Bernoulli layered beam element for planar RC frames, allowing for a physically-based representation of stirrup confinement effects in concrete. In the proposed scheme, the stresses and their nonlinear, multi-dimensional evolution in concrete are determined as a function of the beam geometry, the yield function and the hardening/softening behaviour of each material. Additionally, the ultimate strain in concrete is taken as function of the hydrostatic stress, following an experimentally-inspired relationship (Imran and Pantazopoulou 1996).

Examples of structural computations were presented in which the influence of stirrups on the structural behaviour was shown to be captured properly with respect to previously conducted experiments. This work allows drawing the following main conclusions.

- Capturing the stirrup confinement effects is achieved by the coupling of (i) the transversal equilibrium conditions using a multi-dimensional yield surface for concrete (responsible for the gain in stress levels) and (ii) the increase of the ultimate strain of concrete, defined here as a function of the hydrostatic stress. These result in higher structural strength and ductility and the capacity of the confined concrete volume to dissipate more energy during degradation.

- A satisfying agreement between the predictions of the numerical formulations and experimental structural response for several concrete grades was obtained using a physically sound modelling parameter set in Sect. 3.2.

- An increase of around $25 \%$ in the concrete axial stress in the confined core has been observed numerically, compared to layers without confinement.

- Matching the experimental data, an increase factor of 5 in the vertical displacement at mid-span at failure was observed when stirrups were considered in the simulations of the four point bending test.

- Coupled with the increase in the stress levels this leads to a higher capacity of the structural member to dissipate energy until failure (more than $80 \%$ higher than in the uniaxial compression case).

- With the values used for the material parameters governing the evolution of the ultimate strain in concrete, both developed stirrup models produce similar structural responses. The local stress state in the confined concrete core is then however different, with 
the out-of-plane transversal stress taking significantly higher values in the constant out-of-plane strain stirrup formulation.

In the present layered beam methodology the accuracy of the generalized stress computation depends critically on $n_{\text {lay }}$. The use of a different numerical integration scheme of the layer stresses in the beam cross-section is part of future work aiming for accuracy with a potentially lower computational cost. In the current work the experimental data was carefully chosen to present failure modes that a layered Bernoulli beam formulation is capable of reproducing. A layered beam finite element based on the Timoshenko beam theory would have a wider field of applicability and it is part of future developments. Future work also involves applying the developed stirrup models for the study of larger structures and further assessment of which one gives more realistic results. The implementation of an averaged transversal strain formulation yielding constant transversal strains in the stirrups (Petrangeli et al. 1999) is envisioned together with the inclusion of an adequate bond slip model (Oliveira et al. 2008; Santos and Henriques 2015).

\section{Authors' contributions}

TJM contributed to the formulation of the incorporation of the 3D yield criterion and to the writing, reviewing and enhancement of the manuscript. PZB contributed to the writing and performed the numerical developments and the simulations, including the comparison with experimental data. Both authors read and approved the final manuscript.

\section{Acknowledgements}

The authors also acknowledge the support of F.R.S.-FNRS Belgium (Grant No. 1.5.032.09.F) for the intensive computational facilities used for this work.

\section{Publisher's Note}

Springer Nature remains neutral with regard to jurisdictional claims in published maps and institutional affiliations.

Received: 28 August 2017 Accepted: 25 April 2018

Published online: 26 July 2018

\section{References}

Ahmad, S. M., \& Shah, S. P. (1982). Complete triaxial stress-strain curves of concrete confined by spiral reinforcement. Journal of the Structural Division ASCE, 108, 728-742.

Bao, J. Q., Long, X., Tan, K. H., \& Lee, C. K. (2013). A new generalized DruckerPrager flow rule for concrete under compression. Engineering Structures, $56,2076-2082$

Battini, J.-M. (2002) Corotational beam elements in instability problems (PhD thesis, Royal Institute of Technology).

Biolzi, L., Cattaneo, S., \& Mola, F. (2014). Bending-shear response of self-consolidating and high-performance reinforced concrete beams. Engineering Structures, 59, 399-410.

Breveglieri, M., Aprile, A., \& Barros, J. A. O. (2015). Embedded through-section shear strengthening technique using steel and CFRP bars in RC beams of different percentage of existing stirrup. Computers and Structures, 126, 101-113.
Buyukozturk, O., \& Tseng, T.-M. (1984). Concrete in biaxial cyclic compression. Journal of Structural Engineering ASCE, 110, 461-476.

Chen, W. F. (1982). Plasticity in reinforced concrete. New York: McAraw-Hill Book Company.

Cho, C.-G., \& Park, M.-H. (2003). Finite element prediction of the influence of confinement on RC beam-columns under single or double curvature bending. Engineering Structures, 25, 1525-1536.

Codina, R., Ambrosini, D., \& de Borbón, F. (2016). Alternatives to prevent the failure of RC members under close-in blast loadings. Engineering Failure Analysis, 60, 96-106.

Comi, C. (2001). A non-local model with tension and compression damage mechanisms. European Journal of Mechanics A/Solids, 20, 1-22.

Comi, C., Kirchmayr, B., \& Pignatelli, R. (2012). Two-phase damage modeling of concrete affected by alkali-silica reaction under variable temperature and humidity conditions. International Journal of Solids and Structures, 49, 3367-3380

Crisfield, M. A. (1995). Non linear finite elements analysis of solids and structuresvolume 1: The essentials. London: Wiley.

Cusson, D., \& Paultre, P. (1995). Stress-strain model for confined high-strength concrete. Journal of Structural Engineering ASCE, 121, 468-477.

De Corte, W., \& Boel, V. (2013). Effectiveness of spirally shaped stirrups in reinforced concrete beams. Engineering Structures, 52, 667-675.

Dede, T., \& Ayvaz, Y. (2010). Plasticity models for concrete material based on different criteria including Bresler-Pister. Materials \& Design, 31, 278-286.

Ding, Y., You, Z., \& Jalali, S. (2011). The composite effect of steel fibres and stirrups on the shear behaviour of beams using self-consolidating concrete. Engineering Structures, 33, 107-117.

Gabet, T., Malécot, Y., \& Daudeville, L. (2008). Triaxial behaviour of concrete under high stresses: Influence of the loading path on compaction and limit states. Cement \& Concrete Research, 38, 403-412.

Garzón-Roca, J., Adam, J. M., Calderón, P. A., \& Valente, I. B. (2012). Finite element modelling of steel-caged RC columns subjected to axial force and bending moment. Engineering Structures, 40, 168-186.

Hammoud, R., Yahia, A., \& Boukhili, R. (2014). Triaxial compressive strength of concrete subjected to high temperatures. Journal of Materials in Civil Engineering ASCE, 26, 705-712.

Hong, K. N., \& Han, S. H. (2005). Stress-strain model of high-strength concrete confined by rectangular ties. Journal of Structural Engineering ASCE, 9, 225-232.

Hou, J., \& Song, L. (2016). Progressive collapse resistance of RC frames under a side column removal scenario: The mechanism explained. International Journal of Concrete Structures and Materials, 10, 237-247.

Imran, I., \& Pantazopoulou, S. J. (1996). Experimental study of plain concrete under triaxial stress. ACI Materials Journal, 93, 589-601.

Kent, D. C., \& Park, R. (1971). Flexural members with confined concrete. Journal of the Structural Division ASCE, 97, 1969-1990.

Lew, H. S., Bao, Y., Sadek, F., Main, J. A., Pujol, S., \& Sozen, M. A. (2011). An experimental and computational study of reinforced concrete assemblies under a column removal scenario. NIST Technical Note 1720.

Lim, K.-M., Shin, H.-O., Kim, D.-J., Yoon, Y.-S., \& Lee, J.-H. (2016). Numerical assessment of reinforcing details in beam-column joints on blast resistance. International Journal of Concrete Structures and Materials, 10, S87-S96.

Lu, X. (2005). Uniaxial and triaxial behavior of high strength concrete with and without steel fibers (PhD thesis, New Jersey Institute of Technology).

Malécot, Y., Daudeville, L., Dupray, F., Poinard, C., \& Buzaud, E. (2010). Strength and damage of concrete under high triaxial loading. European Journal of Environmental and Civil Engineering, 14, 777-803.

Mander, J. B., Priestley, M. J. N., \& Park, R. (1988a). Theoretical stress-strain model for confined concrete. Journal of Structural Engineering ASCE, 114, 1804-1826.

Mander, J. B., Priestley, M. J. N., \& Park, R. (1988b). Observed stress-strain behavior of confined concrete. Journal of Structural Engineering ASCE, 114 1827-1849

Menchel, K., Massart, T. J., Rammer, Y., \& Bouillard, Ph. (2009). Comparison and study of different progressive collapse simulation techniques for RC structures. Journal of Structural Engineering ASCE, 135, 685-697.

Mullapudi, T. R., \& Ayoub, A. (2010). Modeling of the seismic behavior of shear-critical reinforced concrete columns. Engineering Structures, 32, 3601-3615. 
Mullapudi, T. R. S., \& Ayoub, A. (2013). Analysis of reinforced concrete column subjected to combined axial, flexure, shear and torsional loads. Journal of Structural Engineering ASCE, 139, 561-573.

Oliveira, C. E. M. (2015). The influence of geometrically nonlinear effects on the progressive collapse of reinforced concrete structures (PhD thesis, Universidade Federal de Ouro Preto).

Oliveira, C. E. M., Batelo, E. A. P., Berke, P. Z., Silveira, R. A. M., \& Massart, T. J. (2014). Nonlinear analysis of the progressive collapse of reinforced concrete plane frames using a multilayered beam formulation. IBRACON Structures and Materials Journal, 7, 845-855.

Oliveira, R. S., Ramalho, M. A., \& Corrêa, M. R. S. (2008). A layered finite element for reinforced concrete beams with bond-slip effects. Cement \& Concrete Composites, 30, 245-252.

Park, R., Priestley, M. J. N., \& Gill, W. D. (1982). Ductility of square-confined concrete columns. Journal of the Structural Division ASCE, 108, 929-950.

Petrangeli, M., Pinto, P. E., \& Ciampi, V. (1999). Fiber element for cyclic bending and shear of RC structures. I: Theory. Journal of Engineering Mechanics, 125, 994-1001.

Petrone, F., Shan, L., \& Kunnath, S. K. (2016). Modeling of RC frame buildings for progressive collapse analysis. International Journal of Concrete Structures and Materials, 10, 1-13.

Rashidian, O., Abbasnia, R., Ahmadi, R., \& Nav, F. M. (2016). Progressive collapse of exterior reinforced concrete beam-column sub-assemblages: Considering the effects of a transverse frame. International Journal of Concrete Structures and Materials, 10, 479-497.

Richart, F. E., Brantzaeg, A., \& Brown, R. L. (1928) A study of the failure of concrete under combined compressive stresses. Engineering Experiment Station, University of Illinois, Urbana, Bulletin No. 185.

Richart, F. E., Brantzaeg, A., \& Brown, R. L. (1929). The failure of plain and spirally reinforced concrete in compression. Engineering Experiment Station, University of Illinois, Urbana, Bulletin No. 190

Saatcioglu, M., \& Razvi, S. R. (1992). Strength and ductility of confined concrete. Journal of the Structural Division ASCE, 118, 1590-1607.

Santafé Iribarren, B., Berke, P., Bouillard, Ph, Vantomme, J., \& Massart, T. J. (2011). Investigation of the influence of design and material parameters in the progressive collapse analysis of RC structures. Engineering Structures, 33, 2805-2820
Santos, J., \& Henriques, A. A. (2015). New finite element to model bond-slip with steel strain effect for the analysis of reinforced concrete structures. Engineering Structures, 86, 72-83.

Sargin, M. (1971). Stress-strain relationship for concrete and the analysis of structural concrete section (PhD thesis, University of Waterloo)

Saritas, A., \& Filippou, F. C. (2009). Numerical integration of a class of 3D plasticdamage concrete models and condensation of 3D stress-strain relations for use in beam finite elements. Engineering Structures, 31, 2327-2336.

Scott, B. D., Park, R., \& Priestley, M. J. N. (1982). Stress-strain behaviour of concrete confined by overlapping hoops at low and high strain rates. Journal of American Concrete Institute, 79, 13-27.

Sfer, D., Carol, I., Gettu, R., \& Etse, G. (2002). Study of the behavior of concrete under triaxial compression. Journal of Engineering Mechanics, 128, $156-163$.

Sheikh, S. A., \& Uzumeri, S. M. (1980). Strength and ductility of tied concrete columns. Journal of the Structural Division ASCE, 106, 1079-1102.

Simo, J. C., \& Taylor, R. L. (1985). Consistent tangent operators for rate independent plasticity. Computer Methods in Applied Mechanics and Engineering, 48, 101-118.

Stramandinoli, R. S. B., \& La Rovere, H. L. (2012). FE model for nonlinear analysis of reinforced concrete beams considering shear deformation. Engineering Structures, 35, 244-253.

Tan, T. H. (2005). Effects of triaxial stress on concrete. In 30th conference on our world in concrete \& structures.

Xiao, Y. (1989). Experimental study and analytical modeling of triaxial behavior of confined concrete (PhD thesis, Kyushu University).

Zendaoui, A., Kadid, A., \& Yahiaoui, D. (2016). Comparison of different numerical models of RC elements for predicting the seismic performance of structures. International Journal of Concrete Structures and Materials, 10 , $461-478$

Zhou, J. J., Pan, J. L., Leung, C. K. Y., \& Li, Z. J. (2014). Experimental study on mechanical behavior of high performance concrete under multi-axial compressive stress. Science China Technological Sciences, 57, 2514-2522.

\section{Submit your manuscript to a SpringerOpen ${ }^{\odot}$ journal and benefit from:}

- Convenient online submission

- Rigorous peer review

- Open access: articles freely available online

- High visibility within the field

- Retaining the copyright to your article

Submit your next manuscript at springeropen.com 